Gram Positive Pathogens $3^{\text {rd }}$ Edition

Chapter: The Gram-positive bacterial cell wall

By Manfred Rohde

Prof. Dr. Manfred Rohde

Helmholtz Centre for Infection Research, HZI

Central Facility for Microscopy, ZEIM

Inhoffenstrasse 7

D-38124 Braunschweig, Germany

e-mail: manfred.rohde@helmholtz-hzi.de

Tel ++49 (0)531-61814413 


\section{THE GRAM-POSITIVE BACTERIAL CELL WALL}

1. Historical background

2. The bacterial cell wall

2.1. Chemistry of the cell wall backbone

2.2. Biochemical synthesis of the peptidoglycan layer

2.3. Turnover of peptidoglycan

3. Lipoteichoic acids and wall teichoic acids as major constituents of the cell wall

4. Capsule

5. Extracellular vesicles of Gram-positive bacteria

6. A specialized cell wall in Mycobacteria

7. Electron microscopic techniques applied to study morphology of Grampositive bacteria cell envelopes

7.1. Heavy metal coating and shadowing

7.2. Negative-staining

7.3. Conventional embedding

7.4. Cryo-methods

7.4.1. Freeze-fracturing and freeze-etching

7.4.2. High pressure freezing and freeze-substitution (HPF-FS)

7.4.3. Cryo-sections of hydrated vitrified bacteria (CEMOVIS) and CryoFIB-SEM

7.4.4. Cryo-electron tomography

8. Outlook 


\section{The Gram-positive bacterial cell wall}

\section{Historical background}

Back in 1884, the Danish bacteriologist Hans Christian Gram had developed a staining procedure to view stained bacteria under the light microscope (47). His staining method, nowadays simply called Gram-staining, discriminated between a Gram-positive and Gramnegative bacterial cell wall. He introduced a dye, gentian violet, which penetrates over the cell wall and cytoplasmic membrane, thus, staining the cytoplasm of the heat fixed bacteria. After addition of iodine an insoluble complex is formed which is retained by the Gram-positive bacterial cell wall upon addition of a decolorizer such as ethanol. Therefore, Gram-positive bacteria appear almost purple while Gram-negative bacteria retain the dye to a lesser extent or not at all and have to be counterstained with a second dye, safranin or fuchsine, appearing pink or reddish. Noteworthy, some mycobacteria showed an indifferent staining behavior when applied to Gram-staining suggesting that the cell wall of mycobacteria might be somehow different from the other two types. In the following decades, it became obvious that cell walls/cell envelopes turned out to be more diverse and Gram-staining alone often could lead to misinterpretations of the cell wall composition.

Until the early 1950s, when the chemical composition of bacterial cell walls was not known, it was speculated if chitin or cellulose, polymers recognized as providing rigid structures to other organisms, represented also the building material of the bacterial cell wall. In 1951, experiments with phenol-insoluble material from Corynebacterium diphtheria (57) revealed glucosamine and diaminopimelic acid as components of the bacterial cell wall which are associated with polysaccharides. Chemical examination of streptococci cell wall layers highlighted the presence of amino acids and hexosamines in the cell wall extract as well as rhamnose as a main 
component in Gram-positive bacteria $(83,109)$. Systematic analyses of a number of Grampositive bacteria identified the two hexosamines glucosamine and muramic acid as major components together with three prevalent amino acids, namely D-alanine, lysine or diaminopimelic acid and glutamic acid. By then also a typical basic basal unit in Gram-positive cell walls was recognized in which glucosamine and muramic acid are linked with three amino acids via a peptide bond $(27,129)$. Gram-negative bacteria express the identical basal unit. Numerous analysis of other bacteria revealed that each bacterial genus or even species are often characterized by a distinctive pattern of amino acids, amino sugars and sugars connected to the basic basal unit. It was discussed that these differences should give a valuable pattern to discriminate between bacterial genus/species $(28,130)$. Over the following years other compounds of the Gram-positive cell wall were recognized as teichoic acids, which are polyribityl phosphates (8), and lipoteichoic acid. Furthermore, numerous proteins had been found linked to the cell wall.

Staining methods of bacteria for light microscopic examinations have limitations since the resolution is not high enough to reveal structural details. With the advent of transmission electron microscopes (TEMs) in the 1930s and the parallel development of preparation methods for biological samples, electron microscopy imaging of ultrathin sections of embedded bacteria became the method of choice to study bacterial cell walls in detail at high resolutions $(25,65$, $66,67)$. With this methodology, it was possible for the first time to discriminate between the structures of Gram-positive and Gram-negative bacteria based on morphological differences in an image. Firstly, electron microscopic preparation protocols developed for eukaryotic cells or tissues were also applied for bacteria. The most fruitful era started when embedding protocols were customized for bacteria and new kinds of embedding resins became available; for example the Lowicryl resins for low temperature embedding which allowed introducing the progressive lowering of temperature $(P L T)$ method $(1,5,22$,$) . This development was paralleled$ 
by technical inventions, especially cryo-methods in which bacteria are physically fixed instead of chemically, and opened up a new horizon in understanding bacterial cell walls. It should be mentioned that even today new methodologies are arising and push morphological studies towards vitrified and unstained bacteria in a fully hydrated status and therefore in a close-tonature condition. Noteworthy, major developments in electron microscopic methodology required a long time period of invention and testing before the technique was introduced to the market. For example, three-dimensional (3D) electron microscopy was developed appr. 30 years after invention of the TEM. Invention and pre-commercial development of cryo-electron tomography (CET) was brought to the market another 30 years later. Due to the rapid development of computer performance and progress in specialized software, nowadays one can estimate that new imaging techniques are introduced faster. For example, the introduction of cryo-FIB (focused ion-beam) combined with a scanning electron microscope (cryo-FIB-SEM) as a new close-to-nature approach was sold a few years after the first advent of FIB-SEM microscopes for conventional resin embedded biological samples.

\section{The bacterial cell wall}

Bacteria are mostly unicellular organisms, which can be found in a very wide variety of different environments. Therefore, bacterial cell walls deserve special attention because they a) are the essential structure for bacterial viability by protecting against the often hostile environment, b) are composed of unique components found nowhere else in nature, c) are responsible for the shape of the bacteria, d) provide halt for ligands and proteins for adherence to host cells, e) expose receptor sites for drugs or viruses, f) represent the most important sites for attack of antibiotics, g) provide structures for immunological distinction and variation and h) can cause symptoms of disease in animals and humans. 


\subsection{Chemistry of the bacterial cell wall backbone}

The major backbone of the bacterial cell wall is the peptidoglycan, also called murein, which consists of repeating linear units of the disaccharide $\mathrm{N}$-acetyl glucosamine (NAG) linked to Nacetyl muramic acid (NAM). The disaccharides are cross-linked via often flexible pentapeptide amino acid chains forming a mesh like framework (123). Chemically, the peptidoglycan consists of alternating $\beta$-1,4-linked $\mathrm{N}$-acetylglucosamine (GIcNAc; NAG) and $\mathrm{N}$-acetylmuramic acid (MurNAc, NAM, a variant of GlcNAc with a D-lactate attached to the C-3 by an ether bond). Termination of a peptidoglycan strand is achieved at the reducing end by a 1,6-anhydroMurNAc residue, in which the C-1 and C-6 of the sugar backbone are bound through an ether linkage. The appearance of the unusual 1,6-anhydroMurNac is used to determine the end of the strands. The peptide stems are covalently linked to the glycan strands with an amide bond to the carboxyl carbon of the D-lactyl group of MurNAc. One hallmark of the peptidoglycan is that the glycans are conserved across bacterial species whereas the peptide stem is often modified and diverse containing D- amino acids. An L-alanine (L-Ala) is usually found in the first position of the pentapeptide stem from the lactyl group of MurNAc, which can be replaced by glycine or Lserine in some rare exceptions. The second amino acid is mostly occupied by a D-isoglutamic acid (D-iGlu). In Streptococcus pneumoniae this D-iGlu is amidated to yield a D-isoglutamine (D-iGIn) (134). The y-carbon of D-iGlu is bound to the third amino acid. This amino acid in the third position of the peptide stem has the highest diversity among bacteria. Generally one can summarize that in most Gram-negative bacteria and some Gram-positive bacteria, like in Bacilli and Mycobacteria, this third position is occupied by the unusual amino acid mesodiaminopimelic acid (m-Dap). In contrast, in most other Gram-positive bacteria it is usually a Llysine (L-Lys) (see Fig. 1). The peptide stem is finally terminated by two D-alanines (D-Ala), although different $\mathrm{D}$-amino acids can be found in this place, too (123). 
In summary, one hallmark of Gram-positive bacteria is the observed differences in the types of crosslinks in which the peptides are connected to the peptidoglycan. Today more than 100 chemotypes can be distinguished and their differences are based on different linking units and substituents in the peptide chain (114).

Due to its unique chemical structure, the peptidoglycan sacculus forms a very large polymer that can be isolated and viewed even in the light microscope (see Fig. 2). The difference between Gram-negative and Gram-positive bacteria is given by the thickness of the peptidoglycan layer surrounding the cytoplasmic membrane. Gram-positive bacteria exhibit a layer of peptidoglycan strands which can reach a size between $30-100 \mathrm{~nm}$ or even thicker, whereas Gram-negative bacteria show a layer of only a few nanometers (see Fig. 3). While the chemical composition of peptidoglycan and the family of proteins for assembling is known for a number of different bacteria, the overall arrangement of these components in Gram-positive cell walls is not fully solved. For Gram-negative bacteria it has been shown with CET (cryo electron tomography) that individual very thin densities, most probably representing glycan strands, run circumferentially around the long axis of the bacterial cell (42). In contrast, the 3-dimentional arrangement of peptidoglycan in Gram-positive bacteria is still under discussion (124). More or less three different models have been proposed over the years. The first model suggests that glycan strands run circumferentially around the long axis as in Gram-negative bacteria. This model was called the "circumferential" or "layered" model (43). In the second model the glycan strands are supposed to run perpendicular to the bacterial cell wall in a hexagonal lattice, and is called therefore "perpendicular" or "scaffold" model $(31,85)$. This model was proposed on the basis of NMR studies applying a synthetic $2 \mathrm{kDa}$ fragment of the peptidoglycan formed of NAG-NAM (pentapeptide)-NAG-NAM(pentapeptide). NMR revealed that this fragment forms a right handed helix with a periodicity of three NAG-NAM per helix turn. The first two amino acids can adopt a limited number of different conformations (85). Atomic force studies (AFM) with gently disrupted 
sacculi of Bacillus subtilis established the so-called "coiled cable" model. Herein, bundles of glycan strands form thicker moieties of around $50 \mathrm{~nm}$ which run around the cell (53). It should be noted that a model with glycan strands running parallel to the long axis has never been considered because it was unclear how such a sacculus could elongate. In addition, the "coiled cable" model is not considered nowadays since CET did not show any cable-like structures in the thick peptidoglycan layer. These earlier observations might have been based on the fact that isolated peptidoglycan was harvested by boiling of bacteria, opened up by a French Press cell, diluted in water and air dried on mica before AFM imaging was performed.

\subsection{Biochemical synthesis of the peptidoglycan layer}

Synthesis of the peptidoglycan is a three-step mechanism, which is localized at three different locations within a bacterium. The sequential Mur ligase pathway is involved in biosynthesis of the peptidoglycan. The early steps of synthesis start in the bacterial cytoplasm where precursors linked to undecaprenylpyrophosphate (UDP), like UDP-N-acetylmuramylpentapeptide (UDP-NAM) and UDP-N-acetylglucosamine (UDP-NAG), are formed. In a second step UDP-NAM is bound to another cytoplasmic membrane-bound UDP functioning as a transport lipid. This complex is called lipid I and is located at the inner cytoplasmic face of the membrane. Covalent attachment of the second precursor UDP-NAG forms the transport lipid complex lipid II. Then, for example in case of S. aureus, a peptide cross-bridge is attached to the third amino acid in the pentapeptide consisting of 5 glycine residues. Next, the entire lipid II complex is flipped over the cytoplasmic membrane to the extracellular side by a flippase. The precise biochemical process of the flipping mechanism is not yet fully understood. Lipid II is incorporated into nascent growing peptidoglycan by penicillin binding proteins (PBPs) on the extracellular side of the membrane. This third step involves firstly a transglycosylation and 
secondly a transpeptidation reaction performed by PBPs for incorporating new glycans with flexible peptides into the existing peptidoglycan layer $(10,16,110,111,121,122,134)$. For detailed reading of chemical reactions and enzymes involved in this process, please refer to the review of Teo and Roper (134).

\subsection{Turnover of peptidoglycan}

The first report describing the bacterial cell wall turnover was published for the Gram-positive bacterium Bacillus megaterium more than 50 years ago (23). Later on, pulse-chased experiments demonstrated with radioactively labeled cell wall precursors that all studied Grampositive bacteria carry out a cell wall turnover as well as Gram-negative bacteria $(14,34,81$, 107). The model for peptidoglycan growth in Gram-positive bacteria implies an inside-to-outside growth in which newly synthesized peptidoglycan is delivered to the cytoplasmic membrane face of the peptidoglycan layer in a relaxed form. With polymerization and cross-linking, peptidoglycan is moving to the outside of the cell wall and gets stretched due to the high turgor pressure within the bacterial cell (68). Once the maximally stretched peptidoglycans in the outer layers start to age, they are subsequently hydrolyzed by autolysins (117). It was estimated that around $50 \%$ of the total cell wall mass is turned over within one generation. This would have been a massive loss of resources for the bacteria and it was speculated that hydrolyzed constituents of the cell wall might be recycled by bacteria. Indeed, this was found to be the case in Gram-negative bacteria like E. coli and the biochemical pathways are well understood (64, 94). If Gram-positive bacteria would also recycle cell wall material remained unclear. It was found that high amounts of cell wall fragments could be detected in growth medium of exponentially grown Gram-positive bacteria like in Bacillus, Lactobacillus, Listeria and Staphylococcus strains (64). Thus, a robust turnover of cell wall components was established 
but if this correlates with high recycling rates of such compounds was only shown recently. In the early 2010s it was demonstrated that Gram-positive bacteria recycle hydrolyzed cell wall material as do E. coli, although key steps and particular aspects of the involved pathways are less understood. Meanwhile orthologs of E. coli enzymes were found in several Gram-positive bacteria being involved in the biochemical process of cell wall recycling (104). Interestingly, new observations implicate that cell wall recycling is turned on when Gram-positive bacteria reach the transition to stationary phase of growth and not in the exponential growth phase, explaining why massive hydrolyzed cell wall constituents were detected in the exponential phase. Furthermore, it is discussed that in Gram-positive bacteria cell wall recycling is a crucial step for survival in the stationary phase and/or in a resting or persistence phase for pathogenic bacteria $(15,64)$. In addition, it should be noted here that the process of delivering newly synthesized peptidoglycan to the inner side of the cell wall and hydrolyzing "older" peptidoglycan at the outside of the wall has to be in an extremely strongly regulated dynamic equilibrium to ensure bacterial cell growth and division. If this equilibrium is somehow altered and more "older" peptidoglycan is shed from the outside of the cell wall than newly synthesized can be delivered to the inner side of the peptidoglycan layer the layer gets thinner with the consequence that the entire bacterial cell can be lysed by intracellular tugor pressure. In addition, antibiotics like penicillin and cephalosporins might bind better to PBPs and further inhibit the delivery of newly synthesized peptidoglycan resulting in an even thinner peptidoglycan (120).

\section{Lipoteichoic acid and wall teichoic acid as major constituents of the cell wall}

Teichoic acid (TA) represents an important cell wall polymer and is found in many Gram-positive bacteria and was first described in $1958(6,7)$. Today teichoic acids enclose two very abundant 
bacterial cell wall polymers a) lipoteichoic acids (LTA) which are anchored via lipid domains in the cytoplasmic membrane and b) wall teichoic acids (WTA) which are covalently bound in the peptidoglycan layers. Teichoic acids consist of a diverse family of bacterial cell surface glycopolymers chemically defined as phosphodiester-linked polyol repeat units or glycerolphosphate or ribitolphosphate residues. Structurally WTA and LTA expose highly negatively charged properties due to the multiple phosphate groups in the structure and less positively charged groups due to inserted D-alanine residues. LTA shows relatively low differences in the structures of different bacteria, whereas WTA is extremely versatile in its structural groups. Why Gram-positive bacteria produce so much LTA and WTA at the same time is not very well understood. For example, LTA can be deleted but only if bacteria are grown below $30^{\circ} \mathrm{C}$, whereas WTA is dispensable in $B$. subtilis and $S$. aureus under laboratory conditions (29). Deletion of LTA and WTA together is lethal because both cannot compensate for one another anymore $(113,126)$. Therefore, WTA and LTA have to fulfil vital functions and indeed, for $S$. aureus it was shown that loss of WTA results in less colonization and infection in in vivo experiments in the rabbit endocarditis model (127). Based on the chemical structures LTAs are grouped into at least 5 different LTA types. Despite their role in infection other major functions of TA have been established over the last years: a) WTA and LTA can protect against environmental stress (92); b) LTA protects against harmful molecules like antimicrobial peptides and cationic antibiotics, interestingly in the structure of LTA a D-alanine is inserted which is responsible for the protection $(26,99,100)$; c) WTA and LTA are the main controlling mechanism for enzyme activities, especially for autolysins and cation concentrations in the peptidoglycan layer (40); d) WTA is responsible for receptor binding and binding to surfaces in pathogenicity (127); e) LTA directs the right placement of cell division machinery $(50,92)$; $)$ WTA serves as a phage receptor (24) and g) WTA and LTA mediate biofilm formation and binding to medical devices (49). 
Different pathways, despite the fact that LTA and WTA show similarities in structure, perform biosynthesis of LTA and WTA. It is known that the $S$. aureus system needs at least 12 genes for WTA synthesis of the backbone structure of poly-Rbo-P (polyol ribitol phosphate). In contrast, only three genes are involved in synthesis of the LTA backbone poly-Gro-P (polyol glycerol phosphate) (19). For modification of the backbones, numerous other genes are involved in incorporation for example of D-alanine or hexoses. Synthesis of WTA is accomplished in $S$. aureus in 5 different steps. Interestingly, the WTA synthesis pathway share undecaprenylphosphate (UDP) as a common lipid carrier. As mentioned above UDP is also involved in the first steps of peptidoglycan synthesis. Most genes being involved are mostly arranged in gene clusters $(19,20,84,132)$. On the other hand, LTA synthesis starts directly from phosphatidylglycerol, which is located in the cytoplasmic membrane. Synthesis initiates on the glycolipid, which also serves as the membrane anchor for LTA. Therefore, no nucleotide activated precursor like UDP is needed. Again, between different Gram-positive bacteria extensive differences exist in the amount of genes involved, length of the LTA and WTA molecules and modification of the synthesized backbones. For further detailed information on WTA and LTA biosynthesis the reviews by Brown et al. (19) and Percy and Gründling (98) are strongly recommended.

In summary, new studies will shed light on the structural and functional relationships of different LTA and WTA types and their impact on cell division, bacterial cell surfaces, and interaction with host receptors and should allow for the identification of new receptors in the bacteria-host interplay. Furthermore, the role of LTA in inducing immune stimulatory effects will be further developed. Particularly the question of cell tropism should be addressed, since the various differences observed in the chemical structures of LTA and WTA between Gram-positive bacteria might reveal evidence that these molecules might play an important role in cell tropism recognition reactions. 


\section{Capsule}

The capsule represents the outer most layer of a Gram-positive bacterial cell wall. It consists of a gelatinous polymer composed of polysaccharides or polypeptides, or both, and surrounds the entire bacterium with a thick layer. The capsule of Bacillus anthracis for example is composed of polymeric D-glutamic acid, whereas the capsule of Group A streptococci consists of hyaluronic acid a repeat polymer of disaccharides composed of D-glucuronic acid and $\mathrm{N}$-acetyl-Dglucosamine. In a proper capsule the polymer is firmly attached to the cell wall, whereas if the polymer is only loosely attached, the structure is often referred to as a slime layer, which in addition has no repeated pattern. Major functions of a capsule in pathogenic bacteria are firstly, the protection against phagocytosis by, neutrophils or macrophages due to the smooth capsular surface and the highly expressed negative charges; secondly, the prevention of the complement mediated bacterial lysis and thirdly, the contribution to virulence determinants. Furthermore, the capsule composition is responsible for different serotypes, which are especially observed in certain species of Streptococci. In the case of Pneumococci, the different capsule polysaccharides are used as vaccine antigens. The capsule is synthesized and assembled at the cytoplasmic membrane and then extruded or secreted through the cell wall to the outside (133).

Since the major component of the capsule is water it is not easy to preserve such polymeric polysaccharides in a natural state for electron microscopic observation. A method of choice is to introduce a kind of a scaffold within the capsule layers to prevent collapsing through chemical fixation and dehydration. As has been explicitly described several times in this chapter, fully hydrated and vitrified samples give the best close-to-nature view of the dimensions of a given bacterial capsule. Nevertheless, the incorporation of lysine as a positively charged component, which reacts by van der Waals forces with the capsule layer negative charges from the polysaccharides, provides a reasonable method to preserve the capsular ultrastructure in 
ultrathin sections. For a rapid visualization of capsules in a TEM, the capsule can be stained with cationic-coated gold nanoparticles (lysine coated gold nanoparticles). For S. pneumoniae it has been demonstrated that fixation with $1 \%$ formaldehyde gives further support of the capsule structure, whereas fixation with glutaraldehyde results in loss of the capsule structure (52). The bound gold-particles around the bacterium show indirectly the presence of the capsule and its dimensions (see Fig. 4). For ultrathin sections, bacteria are incubated with lysine acetate. The bound lysine, in a second step, reacts with ruthenium red which subsequently is precipitated by osmium tetroxide. The precipitates formed in the capsular layers give reasonable support for preservation of the capsules in different Gram-positive bacteria, which allow for measurements of capsule dimensions or to image the in vivo expressed capsules in blood or organs (52, see Fig. 5).

\section{Extracellular vesicles of Gram-positive bacteria}

Extracellular vesicles (EVs) formed by Gram-negative bacteria are known since the 1960s, whereas reports about EVs from Gram-positive bacteria started scarcely at the beginning of the 1990s $(33,131)$. The entire process of forming extracellular vesicles is nowadays referred to as vesiculogenesis (21). One reason for lack of studies for extracellular vesicles of Gram-positive bacteria might be that it was believed that such vesicles simply could not be generated due to the thick peptidoglycan layer in such bacteria. No decent model was able to explain mechanistically the formation and passage through such a thick peptidoglycan mesh work at that time. EVs from Gram-negative bacteria are often referred to as outer membrane vesicles (OMVs) since they generate by pinching-off as vesicles from outer membranes $(13,115)$. In contrast, extracellular vesicles of Gram-positive bacteria are often called membrane vesicles (MVs). It was reported that OMVs serve as a cargo vehicle for DNA, RNA, virulence factors, 
immunomodulators and adhesions for pathogenic bacteria. Therefore, OMVs are considered as playing an important part in pathogenesis of Gram-negative pathogens $(38,69)$. Both extracellular vesicles have in common that they are formed by a lipid-bilayer that forms an inner lumen in which the varying cargos are engulfed. Vesicle size ranges from 20-500 nm and vesicles are best viewed using a transmission electron microscope (TEM) with negative-staining or by field emission scanning electron microscopy (FESEM). In 2009 the first report about membrane vesicles from $S$. aureus was published. In summary, the study found that membrane vesicles were more or less identical to the described OMVs from Gram-negative bacteria with the exception that MVs exhibit a mostly smaller vesicle size up to appr. $200 \mathrm{~nm}$ when compared to OMVs (71). Noteworthy, MVs from S. pneumonia and L. monocytogenes are considerably smaller when compared to other Gram-positive bacteria suggesting that bacteria synthesize and regulate MVs in different ways $(71,72,93)$.

The generation, translocation and secretion are the main unresolved issues about MVs considering they need to be released through the thick peptidoglycan layer into the environment. Three hypothetical models have been reported or discussed a) vesicles generate from the cytoplasmic membrane in a similar process comparable to pinching-off of OMVs from the outer membrane and are then pushed by the interior turgor pressure through the peptidoglycan layers. This implies that MVs size is small since the diameter is regulated by a) the known particle size exclusion of the given peptidoglycan layer for a specific bacterium, b) cell wall modifying enzymes are released or transported by the MVs thus facilitating a transmigration through the peptidoglycan layers possibly by losing the mesh work at the site of travel, c) transport occurs through channels in the layer which implies that MVs are extremely flexible in morphology, i.e. not being always spherical vesicles, and can be released through much smaller channels then the actual size of the spherical MVs found in the environment (71). Therefore, further investigations are needed to clarify the enigmatic release of MVs through the 
Gram-positive peptidoglycan layers. CET could serve as the method of choice to clarify the transmigration through the peptidoglycan layer since bacteria are snap-frozen and even fast events can be fixed. However, the search for such events in tomograms can be very time consuming.

Nevertheless, more and more evidence is emerging pointing out that MVs of Gram-positive bacteria play an important role in pathogenesis since for $S$. aureus it is reported that MVs contain penicillin-binding proteins, which can block activity of ß-lactam antibiotics. Furthermore, the global regulator MsrR, which is involved in methillicin resistance, was also detected in $S$. aureus MVs. MVs can be considered as Trojan horses being involved in passing on resistance genes among Gram-positive bacteria (108). In addition, several toxins have been found in MVs like listerolysin O (LLO) in L. monocytogenes and pneumolysin (Ply) in S. pneumoniae. Both toxins induce pore formation in the host cells and are therefore important virulence factors for colonization and invasion $(72,93)$. In Group A streptococci, MVs have also been described and its content characterized in detail (see Fig. 6). In summary, not only virulence associated proteins like M1 protein, streptolysin O (SLO) and serine protease HtrA were detected, but also numerous metabolic proteins residing in the streptococcal cytoplasm were identified as well as surface exposed proteins including anchorless surface proteins, lipids and RNA. Furthermore, the involvement of the virulence associated two-component regulator CovRS was demonstrated and loss of CovRS resulted in increased vesicle formation (105).

\section{A specialized cell wall in Mycobacteria}

Mycobacteria are classified as Gram-positive bacteria, although are also referred to as acid-fast bacteria due to the high density of lipids in the cell wall, which prevents an accurate Gramstaining. Thus, the staining is performed with Ziehl-Neelsen stain. The complexity of 
Mycobacteria cell walls is a distinct feature that is not found in other bacteria. Three major macromolecules, peptidoglycan, arabinogalactan and mycolic acids are the building blocks of the mycobacterial cell wall. Structural description of the mycobacterial cell wall was conducted in the 1960s and 1970s and electron microscopy played an important role in describing the unusual morphological structures of the cell wall. The current accepted model of the cell wall is based on studies which identified the mycolyl-arabino-galactan-peptidoglycan complex as the core structure of Mycobacteria (86). This unique arrangement with lipids and proteins being included is responsible for the characteristically important and very efficient permeability barrier of the mycobacterial cell wall, particularly against drugs and provide the basis for the very potent pathogenicity of mycobacteria (see Fig. 7). Due to the presence of a high amount of lipids in the cell wall, earlier studies were confronted with the difficulty of extracting the lipids during the dehydration protocol. Therefore, for a long time it was discussed whether the lipids formed a lipid bilayer in the cell wall, as suggested by Minnikin in 1982 (86). He suggested an asymmetrical membrane to which the mycolic acids are covalently attached as an inner leaflet. The presence of such a lipid bilayer was confirmed by freeze-fracture studies, which clearly defined a second fracture plane, typical for a lipid bilayer. These findings supported the hypothesis of a second bilayer outside the cytoplasmic membrane, even though these studies were performed with Corynebacteria $(101,136)$.

However, the existence of a bilayer outside of the cytoplasmic membrane was still heavily criticized because the proposed bilayer has never been clearly identified in ultrathin sections due to artefact-producing embedding preparations like chemical fixation and dehydration with acetone. Instead, a more or less lucent zone, outer layer, most properly representing lipids and mycolic acids, was detected dividing the mycobacterial cell wall into a triple layer structure composed of the cytoplasmic membrane, cell wall and outer layer (see Fig. 8). This translucent zone is covered with a very thin stainable layer consisting of capsule and attached proteins. Freeze-substitution revealed more or less similar images even though the cell wall appeared 
thinner $(95,96,97)$. A major step forward in elucidating the mycobacterial outer cell wall structure was performed with close-to-nature imaging applying cryo ultrathin sections and CET of fully hydrated and vitrified samples (55). These studies revealed important changes to the current model. Firstly, a lipid bilayer was detected covering the outside of the cell wall and therefore, indicating that mycobacteria express a similar outer membrane resembling Gramnegative bacteria. Secondly, no evidence was found for an asymmetrical membrane, instead, a symmetric membrane and an additional periplasmic space was postulated (136). In addition, it is clear that extractable lipids play a dominant role for mycobacterial membrane integrity and properties.

The mycobacterial peptidoglycan is synthesized as observed in other bacteria, in the cytoplasm, using UDP and is then flipped over the cytoplasmic membrane and inserted in the growing peptidoglycan network by the action of hydrolases and PBPs. Nevertheless, Mycobacteria exhibit a number of differences when compared to model bacteria. Firstly, mycobacterial peptidoglycan is extremely cross-linked, secondly the cross-links are based on up to $80 \%$ of the total peptidoglycan on 3-3 peptide cross-links instead of the 4-3 peptide cross-links found in other bacteria, and thirdly the peptidoglycan backbone shows modifications such as glycolylation's of NAM and amidation of D-Glu and m-DAP $(62,70,74,75,102)$. Furthermore, the mycobacterial peptidoglycan is surrounded by a layer of arabinogalactan, a disaccharide, which has long arabinan polymers attached. Noteworthy, some galactans remain free of arabinan polymers and most important, the arabinan chain ends are branched. These branched ends are the binding partners for the long carbon chains of mycolic acid. These incorporated fatty acids are responsible for the extremely thick waxy coat of mycobacteria and make the mycobacterial cell wall mostly impermeable, contributing to pathogenicity. For detailed reaction and enzymes involved in the process please refer to the review of Jankute et al. (62). 


\section{Electron microscopic techniques applied to study morphology of Gram-positive bacteria cell envelopes}

Since the early 1950s transmission electron microscopy has been applied for studying the morphology and ultrastructure of Gram-positive bacterial cell walls. Surprisingly, even today a single unique method, that would allow studying the ultrastructural details of all the different Gram-positive bacteria under close-to-nature conditions in an electron microscope, is still needed. The newly developed CET might be the current method of choice, though CET bears some drawbacks and restrictions especially when bacteria, with a width of more than 0.4 to 0.5 $\mu \mathrm{m}$, have to be imaged. The new super resolution light microscopy methods like STED (stimulated emission depletion), PALM (photoactivated localization microscopy), SIM (structured illumination microscopy) and TIRF (total internal reflection fluorescence) were all very promising, but a breakthrough was hindered by the limitations when imaging immune fluorescent labeled structures. The expression of fluorescence tags or fluorescence proteins, like GFP proteins, might alter the in vivo biological activities to a certain extent, therefore giving rise to non-accurate localizations within the bacterial cell. If the reader is interested in following this in detail, it is recommended to follow the literature regarding the MreB protein (involved in the bacterial division process) over the last years. Depending on the high resolution imaging method applied, different assumptions about its distribution, arrangement and localization in Bacillus subtilis were made, i.e., looking if MreB forms helices in the bacterial cell or not (39).

Several attempts have been undertaken to elucidate the ultrastructure of Gram-positive cell walls. In early TEM imaging of embedded and ultrathin cut bacteria the preparation scheme included chemical fixation with aldehydes, introduction of heavy metals, dehydration with acetone/ethanol and embedding in suitable resins. All these preparations steps had to be done to cope with the "hostile" environment created by the electron microscope, namely high vacuum 
and bombardment with high-energy electrons resulting in heating up the section. Thus, it is obvious that these treatments might not result in a proper preservation of the native cell wall. To overcome some of these detrimental effects in the preparation of bacteria, cryo-methods have been introduced like freeze-substitution or hydrated cryo-ultrathin sections. With the advent of high pressure-freezing techniques preservation of bacterial cell wall structures was pushed further in the direction of close-to-nature conditions. Nowadays, CET is the best method to perform imaging in a frozen vitrified hydrated state of the bacteria (91). However, drawbacks of this technique are that it is only available in certain institutes and it needs a sophisticated infrastructure and time for performing in depth analysis. The future will show if the newly developing cryo-focused-ion-beam scanning electron microscopy micromachining (Cryo-FIBSEM) will advance the deciphering of the ultrastructural details of the bacterial cell wall since the examined bacteria are in their fully hydrated condition and physically frozen overcoming the problem of chemical fixation with aldehydes. This technique allows observing lamellas (appr. 10-20 nm in thickness) cut out of the bacterium; thus, gaining access to small ultrastructural details. It should also be mentioned that other techniques like x-ray diffraction and X-ray lithography have been unsuccessful because the bacterial cell wall is not crystalline. Atomic force microscopy (AFM) has also been implemented, but with AFM only the surface of a sample can be imaged and therefore, only limited ultrastructural information was obtainable.

The same restriction holds true for scanning electron microscopy. With the advent of field emission scanning electron microscopes (FESEM) it was possible to study bacterial structures at very high magnification (up to 400,000-fold) and resolution. Nevertheless, FESEM has never been able to provide the amount of ultrastructural details observed with TEM on ultrathin sections. This is simply due to the fact that FESEM reveals only the surface topography of a bacterial cell. Noteworthy, FESEM does not allow discriminating between Gram-positive and Gram-negative bacteria (see Fig. 9). In addition, FESEM samples need to be coated to be 
conductive. This so-called sputter-coating is often the last step in a scanning EM preparation protocol. Samples are usually sputter coated with a thin 5-8 $\mathrm{nm}$ film of either gold, gold palladium or platinum. Even though these layers are very thin, it might cover some fine ultrastructural details of interest when observed at high magnifications. Surprisingly images at high resolution of the Gram-positive cell wall do more or less not exist. On the other side, FESEM has been very useful in studying pathogenic bacteria interactions with host cells.

In the following a general description of most of the electron microscopic methods applied for studying the bacterial surface structures will be given. If the reader is interested in fully detailed protocols please refer to specialized text books for electron microscopic methods.

\subsection{Heavy metal coating or shadowing}

When biological samples were examined for the first time under a TEM it became obvious that the contrast of the biological material is fundamental and that methods had to be developed to increase the contrast for TEM images. One of the first approaches applied was metal coating with heavy metals $(87,128)$. A shadow line behind the exposed structures appeared when the metal coating was performed under a certain angle. Knowing the coating angle and the measured length of the resulting shadow, the height of the structure could be determined. In earlier years, metal coating had become the method of choice for the ultrastructural description of regularly patterned cell wall structures, named S-layers, attached to the cell wall of bacteria $(6,60,61,116)$.

\subsection{Negative-staining}


The metal coating approach has its restrictions when macromolecules or protein complexes have to be imaged. For such purposes the idea of embedding macromolecules into heavy metal salts like Na-K-phosphotungstate, and later on uranyl acetate or others, were considered. Advantages of negative-staining are manifold: a) reliable and repeatable, b) fast, c) avoids flattening of macromolecules on the support film when air-drying, e) stabilizes the protein in the electron beam, f) allows to determine the shape and quaternary structure of an enzyme complex at around $1.3 \mathrm{~nm}$ resolution and, $\mathrm{g}$ ) usage of different heavy metal salts results in higher or lower contrasts $(4,17,18)$. Noteworthy, negative stained viruses and larger enzymes opened the door for 3D microscopy and image processing beginning in the 1970 s $(41,59)$. Negative staining was the method of choice when isolated peptidoglycan sacculi or pole caps were analyzed (13). Nevertheless, negative-staining is not suitable to differentiate between Gramnegative and Gram-positive bacteria (see Fig. 10).

\subsection{Conventional embeddings}

Since the 1950s, the embedding technique was introduced to analyze the ultrastructural details of bacteria (25) because intact bacteria were unsuitable for these studies. Therefore, ultrathin sectioning of bacteria was needed to gain access to internal morphological structures. With the invention of ultramicrotomes, it was possible to obtain ultrathin sections of biological samples, thus facilitating detailed studies of bacterial cell walls (see Fig. 11).

From then on, morphological studies of bacterial cell walls started to blossom. Ultrathin sections have a thickness of around $50-80 \mathrm{~nm}$, meaning that a single bacterium measuring $1 \mu \mathrm{m}$ in length can be cut into nearly 15 sections. Again, one was directly confronted with the problem of low contrast of biological samples. Thus, the early embedding protocols usually included fixation with aldehydes, contrasting with heavy metals like osmium tetroxide, ruthenium red and uranyl 
acetate, dehydration with acetone/ethanol depending of the resin used for embedding. At that time mostly epoxy or methacrylate resins were used and polymerization was carried out at 60$70^{\circ} \mathrm{C}$. Nowadays, many different resins are available and every class of resin offers a slightly different image of the embedded bacterial ultrastructure, depending on the embedding protocol (see Fig. 12). In addition, the counter-staining of ultrathin sections before TEM examination influences the appearance of ultrastructural details in the sections. These protocols revealed unequivocally the visible differences between Gram-positive and Gram-negative bacterial cell walls. In most of the ultrathin sections, the Gram-positive cell wall appears as an amorphous structure and, depending on the resin and applied embedding protocol; some structural details could be detected like the discussed periplasmic space in Gram-positive cell walls $(12,46)$. It should be clearly stated here that these embedding protocols are prone to induce artifacts in the samples and therefore influence the interpretation of the observed ultrastructural details (44). Nevertheless, these methods served as a basis for most of the description of bacterial ultrastructure and they are widely available in nearly all life science electron microscopy units.

\subsection{Cryo-methods}

Conventional embedding approaches lack the accuracy to investigate tiny ultrastructural details considering potential adverse effects of chemical fixatives, introduction of heavy metals and dehydration during preparations. Cryo-methods began to develop from the beginning of the 1980s onwards, when vitrification of water in biological samples for electron microscopic studies was applied for the first time by Mayer and Brüggeler (82) and Dubochet et al. $(35,36,37)$. Earlier on freeze-fracturing was introduced in the 1960s (88). 


\subsubsection{Freeze-fracturing and freeze etching}

One of the earliest cryo-method applied was freeze-fracturing and freeze-etching. Samples are frozen in nitrogen slush, thereby water in the samples is brought into its vitrified state. Then samples are fractured, sometimes etched and subsequently coated with metal or carbon or both. From this sample a replica is produced which exhibits the surface topography. The depth of the topographical structures depends on the etching time $(58,103)$. Usually, during freezefracture, the fracture line is in the hydrophobic region of a membrane, i.e., in the bacterial cytoplasmic membrane. Thus, exposing transmembrane or membrane bound proteins. Only rarely does a fracture line run across the cell wall or inside a cell wall. Areas which are exposed give a more or less featureless matrix or, as in cross fractures, show a polymeric network which could not be further resolved. These findings did not succeed in gaining considerable new understandings of the Gram-positive cell wall (11).

\subsubsection{High-pressure freezing and freeze-substitution (HPF-FS)}

The development of freeze-substitution of quickly frozen samples, which was paralleled by the invention of low temperature embedding resins as the Lowicryl series of methacrylate resins, was started in the 1980s $(1,22)$. Bacteria are snap-frozen in liquid propane or ethane and then rapidly transferred into a substitution medium containing osmium and/or uranyl acetate in acetone. Remarkably, it was demonstrated that a certain water content in acetone (up to $4 \%$ ) resulted in a much better visibility of membranes (125). Samples are then kept for 2 days at $80^{\circ} \mathrm{C}$, warmed up to $-50^{\circ} \mathrm{C}$ and $-20^{\circ} \mathrm{C}$ and left for 1 day at each step. The following embedding can be performed with low temperature resins, Lowicryl resins, or samples are brought to ambient temperature and embedded with conventional resins $(44,45,96)$. During substitution, 
bacteria are stained and dehydrated resulting in a visibly better preservation of ultrastructural details. Most of freeze-substituted bacteria in ultrathin sections are recognizable by the fact that no distinct DNA region can be observed, whereas, in conventional embedding, DNA mostly aggregates and forms the typical lucent DNA region in the middle of the bacterial cell (see Fig. 13).

Currently, hundreds of substitutions protocols do exist which are customized to fulfil the needs of the examined biological samples and to address the study purpose, e.g., for ultrastructural studies or immune cytochemical localization studies. Freeze-substitution was pushed even more forward by high-pressure freezing of bacteria. This method was developed in the 1960s (88). At ambient temperatures adequate freezing of bacteria is reached with cooling rates of more than $10.000 \mathrm{~K} / \mathrm{s}$ to vitrify the water content in the sample. High pressure is a potent physical cryo-protectant because it lowers the freezing point of water considerably and thicker samples can be vitrified. The currently available equipment freezes samples at appr. 2000 bar. At this pressure, samples of up to $200 \mu \mathrm{m}$ can be frozen without formation of ice crystals (56, $88,118,119)$. The combination of these two methods is nowadays considered to be the best approach for ultrastructural studies on bacteria when no access to CET is possible. One result of such studies is the discussed appearance of a periplasmic space also in Gram-positive bacteria $(79,80,136)$. Nevertheless, CET observations have put these assumptions into question.

\subsubsection{Cryo-sections of hydrated vitrified bacteria (CEMOVIS) and Cryo-FIB-SEM}

Even though high-pressure freezing and freeze-substitution have been a step towards close-tonature conditions, it is without doubt that ultrastructural details and organization of macromolecules are still changing to a certain degree. This occurs because replacement of 
vitrified water and introduction of heavy metals during the substitution process for staining of bacterial components-even when performed in the cold are expected to change native structures. For real close-to-nature observations, water content of samples have to be vitrified to guarantee a fully hydrated status and samples should be observed in the vitrified frozen status below $-80^{\circ} \mathrm{C}$. Hydrated cryo-ultrathin sections fulfill the two criteria (see Fig. 14).

The expression CEMOVIS (cryo-electron microscopy of vitreous sections) has been introduced for this cryo-method (2). Nevertheless, the technique of cutting cryo-ultrathin sections at $-110^{\circ} \mathrm{C}$ or below are very demanding tasks and has been realized only by some laboratories for studying bacterial cell walls $(78,79,80)$. As with nearly every method, cryo-ultrathin sectioning of bacteria also has its drawbacks like knife marks and compressions. For example, forces working during the cutting process, i.e., compression in the cutting direction, can be harmful for preservation of cell wall or lipid membranes $(3,51,135)$. Highly desirable is a method which overcomes the thinning of bacteria without introducing any compression on the sample. Dual beam imaging with a scanning electron microscope (FIB-SEM) with an attached ion gun (focused gallium gun) has been introduced in the 1990s, particularly for material sciences. The ion gun is used to mill away material from a sample which then is imaged by the electron beam with suitable detectors, often so called back-scattered electron detectors (BSE detectors). This is followed by the next cutting step, imaging step and so on. This process is also known as serial block face (SBF) sectioning. Thus, a series of sections is generated which can be aligned and further processed with suitable software to reveal 3D structures of the imaged regions. The usage of ion beam milling was afterwards extended to plastic embedded biological samples like bacteria, eukaryotic cells and tissues $(9,54)$. As early as 2006 a cryo-version of FIB-SEM was invented and was tested for cutting frozen vitrified bacteria with ion milling $(76,77)$. Soon after, cryo-FIB-SEM was introduced to the life sciences field and is now optimized for $2 \mathrm{D}$ and $3 \mathrm{D}$ imaging. Studies highlighted the fact that ion beam milling is an artefact free method without any 
compression to cut vitreous frozen fully hydrated biological samples $(106,112)$. Today, the technique is so advanced that lamellae of a thickness of around $20-30 \mathrm{~nm}$ can be cut out of the vitrified bacteria, transferred to a cryo-TEM and imaged under vitrified conditions. This modern invention allows the performance of CET on such lamellae and $3 \mathrm{D}$ analysis of the cut out lamellae. For this, the next modern electron microscopic imaging technique, namely CET is applied.

\subsubsection{Cryo-electron tomography}

CET also called electron cyrotomography (ECT) reveals structures within a bacterial cell in essential close-to-nature conditions. 3D reconstruction with a TEM can be achieved with a tomographic approach. For this, the sample is tilted mostly between $-70^{\circ}$ to $+70^{\circ}$ around an axis. Every one or two degree tilting step is recorded to collect a $3 \mathrm{D}$ data set. The data set is aligned and the tomogram, a density map, is calculated. Since a 3D view is available, one can scan through every slice in the tomogram and can view structures in this specific slice. The basis for CET is known since the early 1960s, but technical progress for cryo-TEMs had to be invented, like automatization of electron microscopes, electron energy filtering, introduction of highly sensitive slow CCD-cameras for recording images, $300 \mathrm{kV}$ cryo-TEMs, imaging plates and phase-plates for recording of very low signals $(30,48,63,73,89,90)$. One of the major drawbacks is the "bad" signal to noise ratio in CET imaging, thus, again missing contrast in the images is a problem which had to be circumvented.

CET is perfectly suitable for bacteria being not thicker than appr. $300-400 \mathrm{~nm}$ and studying bacterial ultrastructures under close-to-nature conditions. If thicker bacteria need to be imaged the cutting of lamellae from of the sample by cryo-FIB-SEM is the most promising approach. 
Since the image in CET is generated solely by the density of the biological material by itself, most imaging is performed at reasonable underfocus settings to obtain contrast in the images. Therefore, the peptidoglycan layer is in most cases seen as a solid structure without any more details. For example, the membrane bilayer is not represented as conventional embedding images have shown. Nevertheless, by changing and adjusting imaging conditions the outer membrane and cytoplasmic membrane of $E$. coli was clearly visible in reconstructions and new insights were gained into the architecture of mycobacterial cell walls $(42,55)$.

\section{Outlook}

The advent of the described new cryo-approaches should allow examining Gram-positive cell walls under close-to-nature conditions and will certainly help to understand much better the micromorphology of the peptidoglycan together with its attached components. Especially, the discussion of a periplasmic space in Gram-positive bacteria comparable to the one in Gramnegative bacteria should be solved by cryo-methods. It is expected that new and unanticipated structures, which were not seen before, will be made visible. This should occur despite the fact that most cryo-studies performed to dated were with model Gram-positive bacteria laboratory strains of S. aureus, S. pneumoniae and B. subtilis. Once imaging of newly isolated Grampositives from nature will be performed, it should reveal new scenarios of the Gram-positive cell wall. This occurred very recently by Dobro et al. (32) who presented studies of uncharacterized Gram-negative bacterial structures. These structures will certainly open up a new avenue for research. The downside for the implementation and further development of the mentioned cryotechniques is that the equipment for these studies is very expensive and therefore, such electron microscopic platforms might be available only in a few institutions. In addition, the new technology requires experienced personnel, special software and a certain computing 
environment. In addition, researchers have to be convinced that studying the Gram-positive bacterial cell walls is a fascinating research goal and more cryo-approaches are needed to encipher the secrets of the peptidoglycan layers. Nowadays, electron microscopy and fluorescence light microscopy are joining forces in a CLEM (correlative light and electron microscopy) approach in which fluorescent-labeled structures can be made visible and afterwards in CET at high resolution under vitrified conditions. Therefore, CLEM opens up another new field of imaging in which fluorescence labeled structures of interest, even mobile in the bacterial cell, can be followed by live-imaging, snap-frozen at a certain time point and then imaged at high resolution by CET in close-to nature conditions.

\section{References}

1. Acetarin JD, Carlemalm E, Villiger W. 1986. Developments of new Lowicryl resins for embedding biological specimens at even lower temperatures. J Microsc 143:81-88.

2. Al-Amoudi A, Chang JJ, Leforestier A, McDowall A, Salamin LM, Norlen LP, Richter K, Blanc NS, Studer D, Dubochet J. 2004. Cryo-electron microscopy of vitreous sections. EMBO J 23:3583-3588.

3. Al-Amoudi A, Studer D, Dubochet J. 2005. Cutting artefacts and cutting process in vitrifious sections for cryo-electron microscopy. J Struct Biol 150:109-121.

4. Anderson TF. 1962. Negative staining and its use in the study of viruses and their serological reactions. In: Harris RJC (ed) Symposium of the International Society for Cell Biology, vol 1 Academic, New York, pp251-262.

5. Armbruster BL, Carlemalm E, Chiovetti R, Garavito RM, Hobot JA, Kellenberger E, Villiger W. 1982. Specimen preparation for electron microscopy using low temperature embedding resins. J Microsc 126:77-85.

6. Armstrong JJ, Baddiley J, Buchanan JG, Davision AL, Kelemen MV, Neuhaus FC. 1958. Isolation and structure of ribitol phosphate derivatives (teichoic acids) from bacterial cell walls. J Chem Soc1958:4344-4454. 
7. Armstrong JJ, Baddiley J, Buchanan JG, Davision AL, Kelemen MV, Neuhaus FC. 1959. Composition of teichoic acids from a number of bacterial walls. Nature 184:247248.

8. Baddiley J, Buchanan JG, Carss B. 1958. The presence of ribitol phosphate in bacterial cell walls. Biochim Biophys Acta 27:220.

9. Ballerini M, Milani M, Batani M, Squadrini F. 2001. Focused ion beam techniques for the analysis of biological samples: a revolution in ultramicroscopy? Proc SPIE 4261:92104.

10. Barreteau H, Kovac A, Boniface A, Sova M, Gobec S, Blanot D. 2008. Cytoplasmic steps of peptidoglycan biosynthesis. FEMS Microbiol 32:168-207.

11. Beveridge JT. 1981. Ultrastructure, chemistry, and function of the bacterial cell wall. Int Rev Cytol 12:229-317.

12. Beveridge J. 1995. The periplasmic space and the periplasm in gram-positive and gram-negative bacteria. ASM News 61:125-130.

13. Beveridge J. 1999. Structures of gram-negative cell walls and their derived membrane vesicles. J Bacteriol 181:4725-4733.

14. Boothby D, Daneo-Moore L, Higgins ML, Coyette J, Shockman GD. 1973. Turnover of bacterial cell wall peptidoglycans. J Biol Chem 248:2161-2169.

15. Borisova M, Gaupp R, Duckworth A, Schneider A, Dalügge D, Mühleck M, Deubel D, Unsleber S, Yu W, Muth G, Bischoff M, Götz F, Mayer C. 2016. Peptidoglycan recycling in Gram-positive bacteria is crucial for survival in stationary phase. MBio 7:e00923-16.

16. Bouhss A, Trunkfield AE, Bugg TDH, Mengin-Lecreulx D. 2008. The biosynthesis of peptidoglycan lipid-linked intermediates. FEMS Microbiol Rev 32:208-233.

17. Brenner S, Horne RW. 1959. A negative-staining method for high resolution electron microscopy of viruses. Biochim Biophys Acta 34:103-110.

18. Bremer A, Henn C, Engel A, Baumeister W., Aebi U. 1992. Has negative staining still a place in biomacromolecular electron microcopy? Ultramicroscopy 46:85-111.

19. Brown S, Zhang YH, Walker S. 2008. A revised pathway proposed for Staphylococcus aureus wall teichoic acid biosynthesis based on in vitro reconstitution of the intracellular steps. Chem Biol 15:12-21.

20. Brown S, Santa Maria Jr JP, Walker S. 2013. Wall teichoic acids of Gram-positive bacteria. Annu Rev Microbiol 67:313-336. 
21. Brown L, Wolf JM, Prados-Rosales R, Casadevall A. 2015. Through the wall:extracellular vesicles in Gram-positive bacteria, mycobacteria and fungi. Nat Rev Microbiol 13:620-630.

22. Carlemalm E. 1990. Lowicryl resins in microbiology. J Struct Biol 104:189-191.

23. Chaloupka J, Krecková P, Rihová L. 1962. The mucopeptide turnover in the cell walls of growing cultures of Bacillus megaterium KM. Experientia 18:362-363.

24. Chatterjee AN. 1969. Use of bacteriophage-resistant mutants to study the nature of the bacteriophage receptor site of Staphylooccus aureus. J Bacteriol.98:519-527.

25. Chapman GB, Hillier J. 1953. Electron microscopy of ultrathin-sections of bacteria. I. Cellular division in Bacillus cereus. J Bacteriol 66:362-373.

26. Collins LV, Kristian SA, Weidenmaier C, Faigle M, Van Kressel KP, Van Strijp JA, Götz F, Neumeister B, Peschel A. 2002. Staphylocoocus aureus strains lacking Dalanine modifications of teichoic acids are highly susceptible to human neutrophil killing and virulence attenuated in mice $\mathrm{J}$ Infect Dis 180:214-219.

27. Cummins CS, Harris H. 1956. The chemical composition of the cell wall in some grampositive bacteria and its possible value as a taxonomic character. J Gen Microbiol. 14:583-600.

28. Cummins CS, Harris H. 1958. Studies on the cell wall composition and taxanomy of Actinomycetales and related groups. J Gen Microbiol 18:173-189.

29. D’Elia MA, Millar KE, Beveridge TJ, Brown ED. 2006. Wall teichoic acids polymers are dispensable for cell viability in Bacillus subtilis. J Bacteriol 188:8313-8316.

30. Dierksen K, Typke D, Hegerl R, Koster AJ, Baumeister W. 1992. Towards automatic electron tomography. Ultramicroscopy 40:71-87.

31. Dmitriev B, Toukach F, Ehlers S. 2005. Towards a comprehensive view of the bacterial cell wall. Trends in Microbiol 13:569-574.

32. Dobro MJ, Oikonomou CM, Piper A, Cohen J, Guo K, Jensen T, Tadayon J, Donermeyer J, Park Y, Solis BA, Kjaer A, Jewett Al, McDowall AW, Chen S, Chang YW, Shi J, Subramanian P, lancu CV, Li Z, Briegel A, Tocheva EI, Pilhofer M, Jensen GJ. 2017. Uncharacterized bacterial structures revealed by electron cryotomography. J Bacteriol 199:e00100-17.

33. Dorward DW, Caron CF. 1990. DNA is packaged within membrane-derived vesicles of Gram-negative but not Gram-positive bacteria. Appl Environ Microbiol 56:1960-1962.

34. Doyle RJ, Chaloupka J, Vinter V. (1988). Turnover of cell walls in microorganisms. Microbiol Rev 52:554-567. 
35. Dubochet J, McDowall AW. 1981. Vitrification of pure water for electron microscopy. J Microsc 124:RP3-RP4.

36. Dubochet J, Adrian M, Chang JJ, Homo JC, Lepault J, McDowall AW, Schultz P. 1988. Cryo-electron microscopy of vitrified specimens. Q Rev Biophys 21:129-228.

37. Dubochet J. 2016. A reminiscence about early times of vitreous water in electron cryomicroscopy. Biophys J 110:756-757.

38. Ellis TH, Kuehn MJ. 2010. Virulence and immunomodulatory roles of bacterial outer membrane vesicles. Microbiol Mol Biol Rev 74:81-94.

39. Errington J. 2015. Bacterial morphogenesis and the enigmatic MreB helix. Nature Rev Microbiol 13:491-501.

40. Fedtke I, Mader D, Kohler T, Moll H, Nicholson G, Biswas R, Henseler K, Götz F, Zähringer U, Peschel A. 2007. A Staphylococcus aureus ypfP mutant with strongly reduced lipoteichoic acid (LTA) content: LTA governs bacterial surface properties and autolysin activity. Mol Microbiol 65:1078-1091.

41. Frank J. 1989. Image analysis of single molecules. Electron Microsc Rev 2:53-74.

42. Gan L, Chen S, Jensen GJ. 2008. Molecular organization of Gram-negative peptidoglycan. Proc Natl Acad Sci 105:18953-18957.

43. Ghuysen JM. 1968. Use of bacteriological enzymes in determination of wall structures and their role in cell metabolism. Bacteriol Rev 32:425-464.

44. Graham LL, Beveridge TJ. 1990. Evaluation of freeze-substitution and conventional embedding protocols for routine electron microscopic processing of eubacteria. J Bacteriol 172:2141-2149.

45. Graham LL. 1991. Freeze-substitution studies of bacteria. Electron Microsc Res 5:77103.

46. Graham LL, Beveridge TJ. 1994. Structural differentiation of the Bacillus subtilis cell wall. J Bacteriol 176:1413-1421.

47. Gram HC. 1884. Über die isolierte Färbung der Schizomyceten in Schnitt- und Trockenpräparaten. Fortschr Med 2:185-189.

48. Grimm R, Typke D, Baumeister W. 1996. Zero-loss energy filtering under low-down condiitons using a post-column energy filter. J Microsc 183:60-68.

49. Gross M, Cramton S, Götz F, Peschel A. 2001. Key role of teichoic acid net charge in Staphylococus aureus colonization of artificial surfaces Infect Immun 69:3423-3426.

50. Gründling A, Schneewind 0. 2007. Synthesis of glycerol phosphate lipoteichoic acids in Staphylococcus aureus. Proc Natl Acad Sci USA 104:8478-8483. 
51. Han HM, Zuber B, Dubochet J. 2008: Compression and crevasses in vitreous sections under different cutting conditions. J Microsc 230:167-171.

52. Hammerschmidt S, Wolff S, Hocke A, Rosseau S, MüllerE, Rohde M. 2005. Illustration of pneumococcal capsule during adherence and invasion of epithelial cells. Infect Immun 73:4653-4667-

53. Hayhurst EJ, Kailas L,Hobbs JK, Foster SJ. 2008. Cell wall petidoglycan architecture of Bacillus subtilis. Proc Natl Acad Sci USA 105:14603-14608.

54. Heyman JAW, Hayles M, Gestmann I, Giannuzzi LA, Lich B, Subramaniam S. 2006. Site-specific 3D imaging of cells and tissues with a dual beam microscope. J Struct Biol 155:63-73.

55. Hoffmann C, Leis A, Niederweis M, Plitzko JM, Engelhardt H. 2008. Disclosure of the mycobacterial outer membrane: cryo-electron tomography and vitreous sections reveal the lipid bilayer structure. Proc Natl Acad Sci USA 105:3963-3967.

56. Hohenberg H, Mannweiler K, Müller M. 1994. High-pressure freezing of cell suspensions in cellulose capillary tubes. J. Microsc 175:34-

57. Holdsworth ES. 1951. A polysaccharide isolated from Corynebacterium diphtheria. Biochem J 49:xiv.

58. Holt SC, Trüper HG, Takács BJ. 1968. Fine structure of Ectothiorhodospira mobils strain 8113 thylakoids: chemical fixation and freeze-etching studies. Arch Mikrobiol 62:111-128.

59. Hoppe W. Gassmann J, Hunsmann N, Schramm HJ, Sturm M. 1974. Three dimensional reconstruction of individual negatively stained yeast fatty-acid synthetase molecules from tilt series in the electron microscope. Hoppe Seylers Z Physiol Chem 355:1483-1487.

60. Houwink AL. 1953. A macromolecular monolayer in the cell wall of Spirillum spec. Biochim Biophys Acta 10:360-366.

61. Houwink AL. 1956. Flagella, gas vacuoles and cell-wall structure on Halobacterium halobium; an electron microscopic study. J Gen Microbiol 15:146-150.

62. Jankute M, Cox JAG, Harrison J, Besra GS. 2015. Assembly of the mycobacterial cell wall. Annu Rev Microbiol 69:405-423.

63. Jensen GJ, Briegel A. 2007. How electron cryotomography is opening a new window onto prokaryotic ultrastructure. Curr Opin Struct Biol 17:260-267.

64. Johnson JW, Fisher JF, Mobashery S. 2013. Bacterial cell-wall recycling. Ann NY Acad Sci 1277:54-75. 
65. Kellenberger E, Ryter A. 1958. Cell wall and cytoplasmic membrane of Escherichia coli. J Biophys Biochem Cytol 4:323

66. Knaysi G. 1949. Cytology of bacteria II. Bot Rev 15:106-151.

67. Knoll M, Ruska E. 1932. Das Elektronenmikroskop. Z Phys 78:318-339.

68. Koch AL, Doyle RJ. 1985. Inside-to-outside growth and turnover of the wall of Grampositive rods. J Theor Biol 117:137-157.

69. Kuehn MJ, Kesty NC. 2005. Bacterial outer membrane vesicles and the host-pathogen interaction. Gens Dev 19:2645-2655.

70. Lavollay M, The peptidoglycan of stationary-phase Mycobacterium tuberculosis predominantly contains cross-links generated by L,D-transpeptidation. J Bacteriol 190:4360-4366.

71. Lee EY, Choi DY, Kim DK, Kim JW, Park JO, Kim S, Kim SH, Desiderio DM, Kim YK, Kim KP, Gho YS. 2009: Gram-positive bacteria produce membrane vesicles: proteomics-based characterization of Staphylococcus aureus-derived membrane vesicles. Proteomics 9:5425-5436.

72. Lee JH, Choi CW, Lee T, Kim SI, Lee JC, Shin JH. 2013. Transcription factor $\sigma B$ plays an important role in the production of extracellular membrane-derived vesicles in Listeria monocytogenes. PLos One 8:e73196.

73. Lucic V, Förster F, Baumeister W. 2005. Structural studies by electron tomography: from cells to molecules. Annu Rev Biochem 74:833-865.

74. Mahapatra S, Scherman H, Brennan PJ, Crick DC. 2005a. Glycolylation of the nucleotide precursor of peptidoglycan biosynthesis of Mycobacterium spp. is altered by drug treatment. J Bacteriol 187:2341-2347.

75. Mahapatra S, Yagi T, Belisle JT, Espinosa BJ, Hill PJ, McNeil MR, Brennan PJ, Crick DC. 2005b. Mycobacterial lipid II is composed of a complex mixture of modified muramyl and peptide moieties linked to decaprenyl phosphate. J Bacteriol 187:27472757.

76. Marko M, Hsieh C, Moberlychan W, Mannella CA, Frank J. 2006. Focused ion beam milling of vitreous water: prospects for an alternative to cryo-ultramicrotomy of frozenhydrated biological samples. J Microsc 222:42-47.

77. Marko M, Hsieh C, Schalek R, Frank J, Mannella C. 2007. Focused-ion-beam thinning of frozen-hydrated biological specimens for cryo-electron microscopy. Nat Methods 4:2015-2017. 
78. Matias VRF, Al-Amoudi A, Dubochet J, Beveridge TJ. 2003. Cryo-transmission electron microscopy of frozen-hydrated sections of Gram-negative bacteria. J. Bacteriol 185:6112-6118.

79. Matias VRF, Beveridge TJ. 2005. Cryo electron microscopy reveals native polymeric cell wall structure in Bacillus subtilis 168 and the existence of a periplasmic space. Mol Microbiol 56:240-251.

80. Matias VRF, Beveridge TJ. 2006. Native cell wall organization shown by cryo-electron microscopy confirms the existence of a periplasmic space in Staphylococcus aureus. J Bacteriol 188:1011-1021.

81. Mauck J, Chan L, Glaser L. 1971. Turnover of the cell wall of Gram-positive bacteria. J Biol Chem 246:1820-1827.

82. Mayer E, Brüggeller P. 1980. Complete vitrification in pure liquid water and dilute aqueous solutions. Nature 288:569-571.

83. Mc Carty M. 1952. The lysis of group A hemolytic streptococci by extracellular enzymes of Streptomyces albus. II. Nature of the cellular substrate attacked by the lytic enzymes. J Exp Med 96:569.

84. Meredith TC, Swoboda JG, Walker S. 2008. Late-stage polyribitol phosphate wall teichoic acid biosynthesis in Staphylococcus aureus. J Bacteriol 190:3046-3056.

85. Meroueh SO, Bencze KZ, Hesek D, Lee M, Fisher JF, Stemmler TL, Mobashery S. 2006. Three-dimensional structure of the bacterial cell wall peptidoglycan. Proc Natl Acad Sci USA 103:4404-4409.

86. Minnikin DE. 1982. Lipids: complex lipids, their chemistry, biosynthesis and roles, $p$. 95-184. In C Ratledge and J Stanford (eds). The biology of the mycobacteria, vol 1. Physiology, identification and classification. Academic Press, Inc, NewYork, NY.

87. Müller HO. 1942. Die Ausmessung der Tiefe übermikroskopischer Objekte. KolloidZeitschrift 99:6-28.

88. Moor H, Riehle U. 1968. Snap-freezing under high pressure: A new fixation technique for freeze-etching. Proc. Fourth Europ Reg Conf Elect Microsc 2:33.

89. Morris DM, Jensen GJ. 2008. Toward a biomechanical understanding of whole bacterial cells. Annu Rev Biochem 77:583-613.

90. Nagayama K, Danev R. 2009. Phase-plate electron microscopy:a novel imaging tool to reveal close-to-life nano-structures. Biophys Rev 1:37-42.

91. Oikonomou CM, Chang YW, Jensen GJ. 2016. A new view into prokaryotic cell biology from electron cryotomography. Nat Rev Microbiol 14:205-220. 
92. Oku Y, Kurokawa K, Matsuo M, Yamada S, Lee BL, Sekimizu K. 2009.Pleiotropic roles of polyglycerolphosphate synthase of lipoteichoic acid in growth of Staphylococcus aureus cells. J Bacteriol 191:141-151.

93. Olaya-Abril A, Prados-Roslaes R, McConnell MJ, Martin-Pena R, González-Reyes JA, Jiménez-Mungia I, Gómez-Gascón L, Fernández J; luque-Garcia JL, GarciaLidón C, Estévez H, Pachón J, Obando I, Casadevall A, Pirofski LA, RodriguezOrtega MJ. 2014. Characterization of protective extracellular membrane-derived vesicles produced by Streptococcus pneumoniae. J Proteomics 106:46-60.

94. Park JT, Uehara T. 2008. How bacteria consume their own exoskeletons (turnover and recycling of cell wall peptidoglycan. Microbiol Mol Biol Rev 72:211-227.

95. Paul TR, Beveridge TJ. 1992. Reevaluation of envelope profiles and cytoplasmic ultrastructure of mycobacteria processed by conventional embedding and freezesubstitution protocols. J Bacteriol 174:6508-6517.

96. Paul TR, Graham LL, Beveridge TJ. 1993. Freeze-substitution and conventional electron microscopy of medically-important bacteria. Rev Microbiol 4:65-72.

97. Paul TR, Beveridge TJ. 1994. Preservation of surface lipids and ultrastructure of Mycobacterium kansanii using freeze-substitution. Infect Immun 62:1542-1550.

98. Percy MG, Gründling A. 2014. Lipoteichoic acid synthesis and function in Grampositive bacteria. Annu Rev Microbiol 68:81-100.

99. Peschel A, Otto M, Jack RW, Kalbacher H, Jung G, Götz F. 1999. Inactivation of the $\mathrm{dtl}$ operon in Staphylococcus aureus confers sensitivity to defensins, protegrins and other antimicrobial peptides. J Biol Chem 274:8405-8410.

100. Peschel A, Vuong C, Otto M, Götz F. 2000. The D-alanine residues of Staphlyococcus aureus teichoic acids alter the susceptibility to vancomycin and the activity of autolysins. Antimicrob Agents Chemother 44:2845-2847.

101. Puech V, Chamie M, Lemassu A, Lanéelle MA, Schiffler A, Gounon P, Bayan N, Benz R, Daffé M. 2001. Structure of the cell envelope of corynebacteria: importance of the non-covalently bound lipids in the formation of the cell wall permeability barrier and fracture plane. Microbiol 147:1365-1382.

102. Raymond JB, Mahapatra S, Crick DC, Pavelka MS. 2005. Identification of the namH gene encoding the hydroxylase responsible for the $\mathrm{N}$-glycolylation of the mycobacterial peptidoglycan. J Biol Chem 280:326-333.

103. Reimer L, Schulte C. 1966 Elektronenmikroskopische Oberflächenabdrücke und ihr Auflösungsvermögen. Naturwissenschaften 53:489-497.

104. Reith J, Mayer C. 2011. Peptidoglycan turnover and recycling in Gram-positive bacteria. Appl Microbiol Biotechnol 92:1-11. 
105. Resch U, Tsatsaronis JA, Le Rhun A, Stübiger G, Rohde M, Kasvandik S, Holzmeister S, Tinnefeld P, Wai SN, Charpentier E. 2016. A two-component regulatory system impacts extracellular membrane-derived vesicle production in Group A streptococcus. MBio 7:e00207-16.

106. Rigort A, Bäuerlein FJB, Villa E, Eibauer M, Laugks T, Baumeister W, Plitzko JM. 2012. Focused ion beam micromachining of eukaryotic cells for cryoelectron tomography. Proc Natl Acad Sci USA 109:4449-4454.

107. Rogers HJ. 1967. The structure and biosynthesis of the components of the cell walls of Gram-positive bacteria. Folia Microbiol 12:191-200.

108. Rossi J, Bischoff M, Wada A, Berger-Bachi B. 2003. MsrR, a putative cell envelopeassociated element involved in Staphylococus aureus saaarA attenuation. Antimicrob Agents Chemother 47:2558-2564.

109. Salton MRJ. 1952. Studies of the bacterial cell wall. III. Preliminary investigations of the chemical constitution of the cell wall of Streptococcus faecalis. Biochim Biophys Acta 8:510.

110. Sauvage E, Kerff F, Terrak M, Ayala JA, Charlier P. 2008. The penicillin-binding proteins: structure and role in peptidoglycan biosynthesis. FEMS Microbiol Rev 32:234258.

111. Scheffers DJ, Pinho MG. 2005. Bacterial cell wall synthesis: new insights from localization studies. Microbiol Mol Biol Rev 69:585-607.

112. Schertel A, Snaidero N, Han HM, Ruhwedel T, Laue M, Grabenbauer M, Möbius W. 2013. Cryo FIB-SEM: Volume imaging of cellular structure in native frozen specimens. J Struct Biol 184:355-360.

113. Schirner K, Marles-Wright J, Lewis RJ, Errington J. 2009. Distinct and essential morphogenic functions for wall- and lipo-teichoic acids in Bacillus subtilis. EMBO J 28:830-842.

114. Schleifer KH, Kandler O. 1972. Peptidoglycan types of bacterial cell walls and their taxonomic implications Bacteriol Rev 36:407-477.

115. Schwechheimer C, Kuehn MJ. 2015. Outer membrane vesicles from Gram-negative bacteria: biogenesis and functions. Nat Rev Microbiol 13:605-619.

116. Sleytr UB. 1978. Regular arrays of macromolecules on bacterial cell walls: structure, chemistry, assembly, and function. Int Rev Cytol 53:1-64.

117. Smith TJ, Blackman SA, Forster SJ. 2000. Autolysins of Bacillus subtilis: multiple enzymes with multiple funtions. Microbiology 146:249-262. 
118. Studer D, Michel M, Müller M. 1989. High pressure freezing comes of age. Scanning Microsc Suppl 3:253-268.

119. Studer D, Graber W, Al-Amoudi A, Eggli P. 2003. A new approach for cryo-fixation by high-pressure freezing. J Microsc 203:285-294.

120. Sugai M, Yamada S, Nakashima S, Komatsuzawa H, Matsumoto A, Oshida T, Suginaka H. 1997. Localized perforation of the cell wall by a major autolysin: atl gene products and the onset on penicillin-induced lysis of Staphylococcus aureus. J Bacteriol 179:2958-2962.

121. Teo ACK, Roper DI. 2015. Core steps of membrane-bound peptidoglycan biosynthesis: recent advances, insight and opportunities. Antibiotics 4:495-520.

122. Van Heijenvoort J. 2007. Lipid intermediates in the biosynthesis of bacterial peptidoglycan Microbiol Mol Biol Rev 71:620-635.

123. Vollmer W, Blanot D, de Pedro MA. 2008. Peptidoglycan structure and architecture. FEMS Microbiol Rev 32:149-167.

124. Vollmer W, Seligmann SJ. 2010. Architecture of peptidoglycan: More data and more models. Trends in Microbiol 18:59-66.

125. Walther P, Ziegler A. 2002. Freeze substitution of high-pressure frozen samples: the visibility of biological membranes is improved when the substitution medium contains water. J Microsc 208:3-10.

126. Weidenmaier C, Kokai-Kun JF, Kristian SA, Chanturyia T, Kalbacher H, Gross M, Nicholson G, Neumeister B, Mond JJ,, Peschel A. 2004. Role of teichoic acids in Staphylococcus aureus nasal colonization, a major risk factor in nocosomial infections. Nat Med 10:243-245.

127. Weidenmaier C, Peschel A, Xiong YQ, Kristian SA, Dietz K, Yeaman MR, Bayer AS. 2005. Lack of wall teichoic acids in Staphylococcus aureus leads to reduced interactions with endothelial cells and to attenuated virulence in a rabbit model of endocarditis. J Infect Dis 191:1771-1777.

128. Williams RC, Wyckoff RWG. 1945. Electron shadow micrography of the tobacco mosaic virus protein. Science 101:594-596.

129. Work E. 1957. Biochemistry of the bacterial cell wall. Nature 179:841-847.

130. Work E, Dewey DL. 1953. The distribution of alpha, epsilon-diaminopimelic acid among various micro-organisms. J Gen Microbiol 9:394-406.

131. Work E, Knox KW, Vesk M.1966. The chemistry and electron microscopy of an extracellular lipopolysaccharide from Escherichia coli. Ann NY Acad Sci 133:438-449. 
132. Xia G, Kohler T, Peschel A. 2010. The wall teichoic acid and lipoteichoic acid polymers of Staphylococus aureus. Int J Med Microbiol 300:148-154.

133. Yother J. 2011. Capsule of Streptococcus pneumonia and other bacteria: paradigm for polysaccharide biosynthesis and regulation. Anu Rev Microbiol 65:563-581.

134. Zapun A, Philippe J, Abrahams KA, Signor L, Roper DI, Breukink E, Vernet T. 2013. In vitro reconstitution of peptidoglycan assembly from the Gram-positive pathogen Streptococcus pneumoniae. ACS Chem Biol 8:2688-2696.

135. Zuber B, Haenni M, Ribeiro T, Minning K, Lopes F, Moreillon P, Dubochet J. 2006. Granular layer in the periplasm space of gram-positive bacteria and fine structures of Enterococcus gallinarum and Streptococcus gordonii septa revealed by cryo-electron microscopy of vitreous sections. J Bacteriol 188:6652-6660.

136. Zuber B, Chami M, Houssin C, Dubochet J, Griffiths G, Daffe M. 2008. Direct visualization of the outer membrane of Mycobacteria and Corynebacteria in their native state. J Bacteriol 190:5672-5680.

\section{Figure legends}

Fig. 1 The bacterial cell wall backbone, peptidoglycan; shown are the two glycan strands (in black) and peptide stems are depicted in black (left side) and the second peptide stem in blue, note the cross-linking $\mathrm{NH}$ (in red) via the two unusual amino acids m-diaminopimelic acid (mDap in red) and the presence of D-alanine in the peptide stems; two more peptide stems (green and pink) are depicted which can interact to build the next cross-linking between glycan strands.

Fig. 2 Transmission electron microscopic image taken at an acceleration voltage of $80 \mathrm{kV}$ of a peptidoglycan sacculus of $E$. coli after boiling for $3 \mathrm{~h}$ in $10 \%$ SDS. The mesh like sacculus was negatively stained with $1 \%$ aqueous uranyl acetate, air-dried and observed in a normal TEM. 
Fig. 3 Schematic drawing of Gram-negative and Gram-positive cell walls; a characteristic of Gram-negative cell walls is the presence of two membranes i) the cytoplasmic membrane and ii) the outer membrane, between both membranes the periplasmic space is found in which a very thin layer of peptidoglycan is found; attached to the outer membrane are lipopolysaccharides and in the outer membrane porins are inserted. A thick layer of peptidoglycan and the lack of an outer membrane are the main characteristics of Gram-positive cell walls; instead of lipopolysaccharides Gram-positive bacteria have lipoteichoic acid and teichoic acid localized in the cell wall. The discussed periplasmic space is not drawn since the existence of such a periplasm in Gram-positive bacteria is still ongoing.

Fig. 4 Visualization of Gram-positive bacterial capsules. A) cationic gold nanoparticles (lysine coated $15 \mathrm{~nm}$ gold nanoparticles) label the thick capsule of Streptococcus pneumoniae after fixation with $1 \%$ formaldehyde at low $\mathrm{pH}$ (stars), B) cryo-FESEM at close-to-nature conditions reveals the thick capsule layer of $S$. pneumoniae marked with white stars, the thickness is comparable to the labeled capsule in A; samples were nitrogen slush frozen, freeze-fractured at $-105^{\circ} \mathrm{C}$, freeze-etched at $-105^{\circ} \mathrm{C}$ for $30 \mathrm{sec}$ and sputter coated with gold/palladium, C) for ultrathin sections capsules can be preserved with lysine-ruthenium-red osmium embedding protocol (see 52) followed by embedding in LRWhite resin, Streptococcus suis is surrounded by a dense capsule layer (white stars).

Fig. 5 Good preservation of streptococcal capsules under in vivo conditions. A) Streptococcal capsules (Streptococcus pyogenes administered i.v.) are well preserved (black stars) in spleen under in vivo conditions in the mouse model even after fixation with glutaraldehyde and 
formaldehyde, dehydration with acetone and embedding in epoxy resin and ultrathin sectioning, B) enlargement of another bacterium depicting nicely preserved capsule (black stars). Most likely proteins in the blood have covered and preserved the capsule and prevent loss of capsule during aldehyde fixation.

Fig. 6 Formation of membrane vesicles (MVs) on the surface of Streptococcus pyogenes M1 serotype imaged with FESEM after chemical fixation with aldehydes, dehydration with acetone, critical-point drying, and sputter coating with gold/palladium.

Fig. 7 Schematical drawing of a mycobacterial cell wall; characteristic is a thin layer of peptidoglycan and arabinogalactan to which high amounts of mycolic acids are attached; another unusual compound is lipoarabinomannan which is attached to the cytoplasmic membrane, on the outer most outside glycolipids are attached to the mycolic acids, transport is facilitated by inserted porins. The "mycobacterial outer membrane" is not drawn in the scheme since the presence of such an outer membrane is still under discussion.

Fig. 8 Typical appearance of a triple layer structure of the mycobacterial cell wall of Mycobacterium avium ssp. paratuberculosis after special embedding applying the OTO method (osmium-thiocarbohydrazide(TCH)-osmium); this method especially preserves lipids much better because after the first osmium tetroxide step $\mathrm{TCH}$ binds to the sample bound osmium and in the second osmium step more osmium is bound to $\mathrm{TCH}$, therefore stabilizing lipids; in addition bacteria were embedded applying the PLT method (progressive lowering of temperature) down to $-50^{\circ} \mathrm{C}$ and bacteria are then embedded in the hydrophobic Lowicryl resin HM20; this protocol allows to clearly define the triple layer structure of the mycobacterial cell 
which is lost in most of all other embeddings despite the cryo-based protocols. CM cytoplasmic membrane, CW cell wall, OL outer layer, OM outer membrane.

Fig. 9 FESEM of aldehyde fixed, acetone dehydrated, critical-point dried and gold/palladium sputter-coated samples. A) Escherichia coli Gram-negative, B) Acinetobacter baumannii Gramnegative, C) Streptococcus pyogenes Gram-positive and D) Enterococcus faecium Grampositive. Since FESEM reveals only the surface structures and no information from inside the bacteria FESEM does not allow distinguishing between Gram-negative and Gram-positive bacteria.

Fig. 10 Transmission electron microscopic images of negatively stained bacteria. A) Escherichia coli, Gram-negative and B) Streptococcus gordonii, Gram-positive; negative staining with $1 \%$ aqueous uranyl acetate cannot discriminate between Gram-negative and Gram-positive bacteria because the different peptidoglycan thicknesses cannot be resolved.

Fig. 11 Typical image of a conventional embedded Gram-positive bacterium, Streptococcus pneumoniae, after aldehyde fixation, contrasting with osmium tetroxide and uranyl acetate, dehydration and embedding in epoxy resin; in ultrathin sections the DNA region is typically aggregated and forms a translucent area within the bacterial cell; the thick peptidoglycan layers are dark featureless structures. CM cytoplasmic membrane, CW cell wall.

Fig. 12 Comparison of embedding in different embedding resins. A) Staphylococcus aureus embedded in LV resin, B) S. aureus embedded in LRWhite resin. S. aureus was fixed, stained 
with osmium and uranyl acetate during dehydration with ethanol and embedded in the epoxy LV (low viscosity) resin, a replacement of the widely used Spurr resin, and the aromatic acrylic resin LRWhite; both protocols show similar features namley a clearly defined cyoplasmic membrane (CM) and a peptidoglycan with two distinct zones, the dark inner wall zone (IWZ) and the outer wall zone (OWZ) which more translucent appearance; nevertheless, LRWhite resin preserves the OWZ much better compared to LV resin; in addiiton, the cytoplasm of both identically treated bacterial cells looks quite different. LRWhite has proven to represent a reliable resin for studying bacterial ultrastructures.

Fig. 13 Comparison of conventional embedded and high-pressure frozen and freeze-substituted Group G streptococci. A and B) cross section and longitudinal section of dividing bacteria of conventional embedded bacteria, note the prominent translucent DNA region and the absence of any material attached to the outside of the bacterial cell wall, $C$ and D) cross and longitudinal section of high-pressure frozen and freeze-substituted bacteria, no translucent DNA region is detectable anymore and the bacterial cytoplasm appears as an uniform structure throughout, some material attached on the outer side of the bacterial cell wall is also preserved.

Fig. 14 Cryo-electron microscopy of a vitreous ultrathin section (CEMOVIS) of Streptococcus pyogenes; note the very well preserved cytoplasmic membrane (CM) and some structural details can be detected in the peptidoglycan layers of the cell wall (CW, arrow heads) when compared to the dark appearance of cell walls in conventional embedded bacteria (compare to Fig. 11). 
